\section{Telephone based peer support increased duration of breast feeding in primiparous mothers}

Dennis CL, Hodnett E, Gallop R, et al. The effect of peer support on breast-feeding duration among primiparous women: a randomized controlled trial. CMAJ 2002 Jan 8;166:21-8.

\section{QUESTION: Do primiparous, breastfeeding mothers who receive telephone based peer support continue breast feeding longer than women who receive conventional care?}

\section{Design}

Randomised (allocation concealed), blinded (outcome assessor), controlled trial with follow up at 4, 8, and 12 weeks post partum.

\section{Setting}

2 semi-urban community hospitals near Toronto, Ontario, Canada.

\section{Patients}

258 in hospital, primiparous, breastfeeding women who were $\geqslant 16$ years of age, were able to speak English, had a singleton birth at $\geqslant 37$ weeks gestation, and resided in the surrounding region accessible by a local telephone call. Exclusion criteria were factors that could seriously interfere with breast feeding (eg, serious maternal illness or infant congenital abnormality) or prenatal enrolment with the participating volunteer breastfeeding organisation. 256 women (99\%) completed the trial and were included in the analysis. Most (75\%) were between 25 and 34 years of age.

\section{Intervention}

132 women were allocated to the peer support group, which included telephone based peer support in addition to conventional in hospital and community postpartum services (eg, a hospital based breastfeeding clinic and support services by public health nurses). Each new mother was paired with a peer volunteer (ie, a mother who had $\geqslant 6$ months of previous breastfeeding experience and a positive attitude towards breast feeding, and had completed a $2.5 \mathrm{~h}$ orientation session) on the basis of location of residence and availability. Peer volunteers were asked to contact the new mother within 48 hours after hospital discharge and as frequently thereafter as the mother deemed necessary. 126 women were allocated to conventional care only.

\section{Main outcome measure}

Main outcome was self reported breast feeding (receipt by the infant of any breast milk) in the 24 hours before the interview.

\section{Main results}

Analysis was by intention to treat. Mothers who received peer support were more likely to be breastfeeding at 4,8 , and 12 weeks post partum than were mothers who received conventional care only (table). As well, mothers in the peer support group were more likely to be exclusively breast feeding at 12 weeks (table).

\section{Conclusion}

Primiparous, breastfeeding mothers who received peer support by telephone were more likely to still be breast feeding at 12 weeks post partum than were mothers who received conventional care only.

Peer support v conventional care only for breastfeeding primiparous mothers*

\begin{tabular}{lllll} 
Outcomes & $\begin{array}{l}\text { Peer } \\
\text { support }\end{array}$ & $\begin{array}{l}\text { Conventional } \\
\text { care }\end{array}$ & RBI (95\% Cl) & NNT (Cl) \\
Breast feeding at 4 weekst & $92 \%$ & $84 \%$ & $11 \%(1$ to 16$)$ & 12 (8 to 191$)$ \\
\hline Breast feeding at 8 weekst & $85 \%$ & $75 \%$ & $17 \%(3$ to 25$)$ & 8 (6 to 40$)$ \\
\hline Breast feeding at 12 weeks $\dagger$ & $81 \%$ & $67 \%$ & $25 \%(9$ to 35$)$ & 6 (5 to 17$)$ \\
\hline $\begin{array}{l}\text { Exclusive breast feeding at } \\
12 \text { weeks }\end{array}$ & $57 \%$ & $40 \%$ & $41 \%(9$ to 84$)$ & 7 (4 to 24$)$ \\
\hline
\end{tabular}

*Abbreviations defined in glossary; RBI, NNT, and $\mathrm{Cl}$ calculated from data in article. †Based on adjusted analysis.

\section{COMMENTARY}

Most mothers stop breast feeding before their infants are 6 months old, despite the well documented health benefits for both themselves and their infants. The study by Dennis et al focused on the effect of telephone based peer support on breastfeeding duration. This study was methodologically strong, with random assignment to groups, blinding of the outcome assessor, and follow up of all but 2 mothers. The findings show that telephone based peer support was effective in maintaining breast feeding to 12 weeks post partum. Further study is needed to determine if this intervention is effective in maintaining breast feeding beyond 12 weeks. The study was done within a small geographic area and had a homogeneous sample, so its generalisability to other areas and other populations, particularly younger, less educated, low income, or immigrant women, would need to be evaluated. Because the extent of breast feeding was not associated with the occurrence and frequency of peer support interactions, the authors conclude that a standardised peer support intervention does not appear necessary. Other research both confirms and contradicts this finding. ${ }^{12}$ Differences may be related to the definition and preparation of peer supporters. Further exploration of this issue is necessary to assist with transferability to practice.

A recently updated systematic review ${ }^{3}$ concluded that there was clear evidence for the effectiveness of professional support on the duration of any breast feeding, although the strength of its effect on the rate of exclusive breast feeding is uncertain. It also concluded that lay support is effective in promoting exclusive breast feeding, whereas the strength of its effect on the duration of any breast feeding is uncertain. The authors suggest that consideration be given to providing supplementary breastfeeding support as part of routine health services and that further research be done to assess the effectiveness and cost-effectiveness of both lay and professional support in different settings, especially in communities with low rates of breastfeeding initiation. Nurses have an important role to play in the achievement of these goals, particularly in advocating for and participating in continuing research in this area. The different elements of breastfeeding support strategies and the mechanisms by which support operates should be explored.

Mary Lou Walker, RN, MHSc Family Health Program Manager, Toronto Public Health, Toronto, Ontario, Canada

1 Israel BA. Social networks and social support: implications for natural helper and community level interventions. Health Educ Q 1985;12:65-80.

2 Morrow AL, Guerrero ML, Shults J, et al. Efficacy of home-based peer counselling to promote exclusive breastfeeding: a randomised controlled trial. Lancet 1999;353:1226-31.

3 Sikorski J, Renfrew MJ, Pindoria S, et al. Support for breastfeeding mothers. Cochrane Database Syst Rev 2002;(1);CD001141. 